\title{
ARQUEOLOGÍA Y PATRIMONIO. REFLEXIONES DESDE LA PRÁCTICA
}

\author{
Cristina Bellelli
}

CONICET - INAPL - UBA. E-mail: bellelli@retina.ar

Presentado el: 11/12/2011 - Aceptado 29/02/2012

\section{Introducción}

Estas líneas intentan resumir algunas ideas en torno de la práctica arqueológica y su relación con el patrimonio que el Equipo de Arqueología de la Comarca Andina del Paralelo $42^{\circ}$ viene desarrollando desde hace más de quince años y que han sido presentadas de modo más o menos organizado en otros trabajos (Bellelli 2006, 2007, Bellelli et al. 2010b, Podestá et al. 2009, entre otros). La región donde tienen lugar las experiencias y reflexiones que sintetizo acá abarca el valle inferior del Río Manso (suroeste de Río Negro) y la Comarca Andina del Paralelo $42^{\circ}$ (localidades de El Bolsón, El Hoyo, Lago Puelo, Epuyén y Cholila, en el noroeste del Chubut), donde hasta el momento se conocen más de sesenta sitios arqueológicos con arte rupestre, ubicados todos en ambiente de bosque.

A partir del año 2000 nuestro proyecto de investigación amplió sus objetivos arqueológicos para incorporar aquellos relacionados con la, dicho en términos muy generales, activación patrimonial de ciertos sitios arqueológicos ${ }^{1}$. En el lapso que media entre esa fecha y la actualidad se fueron consolidando algunos lineamientos en este sentido que ya estaban en proceso (como por ejemplo el sitio Cerro Pintado, en Cholila, del que me ocuparé con algo más de detalle acá, o El Radal, cercano a la localidad chubutense de Lago Puelo). También nuevos sitios fueron cobrando interés (los ubicados en los valles de los ríos Epuyén y Manso) o bien en otros no se pudo ni siquiera comenzar a implementar investigaciones (un sitio en El Bolsón y otro en el valle del Epuyén).

Estas experiencias fueron muy diferentes por sus orígenes, problemáticas y objetivos. La alta vulnerabilidad de algunos sitios debida a su cercanía a centros poblados y vías de comunicación o el interés de autoridades municipales o propietarios de las tierras en que se ubican los sitios por incorporarlos a emprendimientos turísticos, fueron algunos de los motivos que hicieron que priorizáramos algunos de los sitios sobre otros. Al encarar esas tareas fuimos guiados por dos conceptos amplios: el interés en la conservación activa de los sitios arqueológicos en tanto patrimonio y no como mero recurso destinado a generar ingresos y/o rédito político, y el convencimiento de que no somos los únicos capaces de darle sentido a ese patrimonio sino que es necesario estar abiertos a otras visiones y otras voces, entre las que se destacan las de aquellos que conviven con ese patrimonio. En este sentido, fuimos llegando al convencimiento de que la conservación no puede lograrse sin el 
compromiso y la participación activa de esos individuos, organizaciones sociales, políticas, administrativas y que el "rédito" que buscamos es que el patrimonio, su conservación y gestión quede en sus manos (Bellelli 2007).

Otro punto que nos preocupó desde los inicios del proyecto fue el de la interpretación, entendiendo que esta y la posterior divulgación, son dos herramientas que pueden colaborar en la protección del patrimonio (Gándara 2009). Principalmente nos interesaba que el modo en que se presenta la información, la manera en que el relato del pasado se vuelca a través de distintas herramientas (visitas guiadas, cartelería, folletos, etc.), hiciera hincapié en que la Patagonia tiene una rica historia previa a la instalación de colonos y pobladores de distinto origen, pero sobre todo europeos, de fines del siglo XIX y principios del XX que, en la versión oficial (y a la vez más divulgada e instalada en el sentido común y también en los planes educativos y los medios de comunicación), se reconocen como "los primeros pobladores". Es cuestión que el relato del pasado que se vuelque en todas las herramientas interpretativas demuestre la profundidad temporal y los grandes cambios culturales y sociales que se dieron en todos los aspectos de las sociedades que dejaron esas marcas en la piedra para lograr que el pasado negado e invisibilizado tome protagonismo.

En diversos trabajos hemos dado a conocer los resultados a los que hemos llegado en nuestras investigaciones arqueológicas, hemos hecho el diagnóstico del estado de preservación y los factores que inciden en el deterioro de los sitios, hemos presentado resultados de experiencias y propuestas de manejo y, publicado los análisis antropológicos que buscan conocer el sentido y la valoración que los pobladores actuales le otorgan a los sitios arqueológicos, hemos producido videos desde la óptica de la antropología visual, generamos múltiples herramientas destinadas a la difusión de las investigaciones a todo nivel y para ser usadas por los encargados de la gestión de los sitios (guiones para las visitas, fichas interpretativas, disco compacto, folletos, cartelería, etc.), además de los talleres participativos, conferencias, charlas, visitas a los sitios, cursos, etc. que forman parte de la práctica del equipo (Bellelli et al. 2000, 2003, 2008, 2010 a y b, Caracotche et al 2010, Crespo 2006, Fernández et al. 2011, Masotta 2001, 2004, 2010, Moscovici Vernieri 2011, Ondelj 2004, 2005, Podestá et al. 2009, Xicarts 2005, entre otros).

Pero acá sólo plantearé sintéticamente una de las experiencias en las que hemos tenido resultados positivos en los aspectos de conservación, interpretación y, fundamentalmente, trabajo conjunto con distintos actores sociales. Se trata de la localidad Cholila (provincia del Chubut), donde se conoce desde hace muchos años el extenso alero con pinturas rupestres Cerro Pintado. Está muy próximo a la ruta de acceso al Parque Nacional Los Alerces y a pocos kilómetros del pueblo, tiene gran visibilidad desde la ruta, el acceso es fácil, etc., todas características que lo colocan en una posición ventajosa para su uso público en relación con otros de la región pero, al mismo tiempo desventajosa en cuanto a su conservación y preservación por ser muy conocido y visitado (Bellelli et al. 2010b, Podestá et al. 2009).

Las investigaciones arqueológicas en Cholila comenzaron en 1995 y sus resultados contribuyeron al conocimiento del uso que le dieron al espacio regional las sociedades cazadoras-recolectoras que lo habitaron desde hace 2000 años (Bellelli et al. 2000, 2003). En esos primeros momentos nos preocupaba más que nada la conservación del sitio y poco a poco fuimos incorporando otro tipo de preguntas a la investigación, ligadas ahora a la relación que se establece (o no) entre el pasado arqueológico y la comunidad y la valoración 
que sus diferentes miembros le dan a los sitios arqueológicos, entre otras temáticas. Para contestar algunas de las preguntas que se iban abriendo se incorporaron al proyecto antropólogos sociales que trabajaron temáticas ligadas a la identidad, la memoria y los usos que la comunidad de Cholila hace de su pasado (Ondelj 2004, 2005, Masotta 2001). Sus resultados nos permitieron tener una visión más clara del valor que el patrimonio tiene para los diferentes actores sociales y fueron aprovechados en las tareas que fuimos realizando y los planes que fuimos proponiendo a las autoridades municipales y al propietario del campo donde se emplaza el sitio.

Desde el principio de las investigaciones hubo interés por parte, sobre todo, de la comunidad educativa de Cholila por conocer los resultados de las investigaciones, que comunicábamos en ocasión de cada trabajo de campo y a través de la distribución de los trabajos escritos. Pero poco a poco nos fuimos involucrando de otras maneras, respondiendo a pedidos concretos de docentes y pobladores, a través de cursos de capacitación a jóvenes de la comunidad. También se comenzó a trabajar en conjunto con el área de Cultura y Turismo de la Municipalidad capacitando promotoras culturales para que se desempeñaran como guías del sitio. Pero las condiciones para visitar el sitio no estarían dadas hasta que no se diseñara y pusiera en ejecución un plan de manejo que involucrara no sólo la capacitación sino también las obras de infraestructura y las pautas para la visitación. Así, se comenzaron las tratativas con el propietario de la Estancia, con una ONG muy activa en la zona y con la Municipalidad para encarar las obras de infraestructura y puesta en valor que fueron realizadas entre todos. A principios de 2005 se abrió el sitio al uso público, comenzando una historia llena de dificultades y de marchas, contramarchas y cambios en la modalidad de visitación que se concentró en los últimos años en las visitas educativas y en visitas turísticas pautadas con anterioridad que realiza la guía profesional que desde hace tres años se hace cargo del tema. Las dificultades se pudieron superar porque se constituyó una Comisión de Sitio que está conformada por representantes del Área de Cultura y del Área de Turismo de la Municipalidad de Cholila, de la Estancia y Cabaña Los Murmullos, la Fundación Mundo Sano y la Guía del Sitio. Nosotras (Mercedes Podestá, Soledad Caracotche y la autora) pasamos entonces, a desempeñar el rol de asesoras en los aspectos científicos relacionados con la significación del sitio en el contexto histórico regional y en la interpretación de la información obtenida en las investigaciones para ser volcada a los visitantes, y en lo técnico asesoramos en todo lo relacionado con el uso público del sitio y, junto con la guía, con las tareas periódicas de monitoreo a fin de supervisar el estado de conservación de las pinturas rupestres y del sitio en su conjunto y tomar las medidas necesarias. Por otra parte, el sitio no está exento de sufrir actos de vandalismo, como sucedió en algunas oportunidades, pero ahora hay una respuesta tanto condenándolos como remediándolos a través de la Comisión de Sitio. Esta se reveló como un órgano dinámico y con poder de decisión, lo cual nos permite a nosotras cumplir el papel de asesoras, dejando en sus manos la solución a muchos problemas que estando a 2000 kilómetros no podemos resolver. Esta es, en apretada síntesis, la experiencia en Cholila (Bellelli et al. 2010b, Podestá et al. 2009).

Las otras experiencias de activación patrimonial que intentamos en la región tuvieron resultados diversos, como adelanté al principio, y todas han tenido características diferentes. En el sitio Risco de Azócar (valle del río Epuyén) que excavamos y relevamos su arte rupestre (Podestá et al. 2007), la familia propietaria de las tierras donde se emplaza, en acuerdo con la política turística de El Hoyo, más orientada al turismo de naturaleza, decidió no darlo a conocer ni incentivar las visitas, constituyendo otro ejemplo del modo en que las personas e instituciones involucradas toman decisiones sobre el manejo del patrimonio. Otras expe- 
riencias las constituyen, en primer lugar, el sitio El Radal, de Lago Puelo, donde se dieron disputas políticas vecinales y provinciales en torno al sitio en las que nos vimos muy involucradas y que todavía no se zanjaron; en segundo término intervenimos también en el sitio emblemático del río Manso (Paredón Lanfré) donde el propietario de las tierras realiza una muy buena gestión, y finalmente las prohibiciones lisas y llanas que tuvimos en Azcona (El Bolsón) y Pataguas (valle del río Epuyén) ${ }^{2}$. Estas características diferentes nos llevaron a buscar caminos alternativos a algunas recetas clásicas en la temática y comenzamos a cuestionar en nuestra práctica los alcances del enfoque patrimonial centrado exclusivamente en valores sostenidos por los científicos o por la legislación estatal, y asumir que no bastaba con las buenas intenciones y los esfuerzos hechos por nosotros para transmitir los valores estéticos e históricos para activar la conservación. Además, disponer de información arqueológica no siempre trae aparejada la valoración y cuidado de los bienes patrimoniales de este tipo por parte de varios sectores de la población, ni su inscripción dentro del pasado considerado propio. Esto se verificó en el Cerro Pintado, donde a partir de las acciones descriptas y sobre todo por la asunción por parte de la Comisión de Sitio de la responsabilidad de su gestión, la visión de los cholilenses acerca de su significado histórico y de sus valores patrimoniales comenzó lentamente a modificarse, lo cual se ve también en la devolución que los visitantes hacen a través del libro de visitantes y/o las encuestas que realiza la guía.

\section{Algunas reflexiones finales}

Como señalé a lo largo de estas líneas nuestro trabajo tiene un interés muy fuerte en la conservación de los sitios y su continuidad en el tiempo. Por lo tanto, su uso público no debe acelerar los procesos naturales de deterioro ni incentivar el vandalismo, para lo cual es clave la organización del manejo y de la gestión. En este sentido, nos involucramos aportando los resultados adquiridos en las investigaciones y las herramientas técnicas destinadas a acompañar y colaborar en el proceso de puesta en valor de los sitios. Esta es, en definitiva, una de las situaciones que pone a los arqueólogos frente a la posibilidad de que el conocimiento que generan sea aprovechado socialmente.

Pero estas acciones, en mayor o menor medida, nunca están exentas de conflictos. La mayoría de éstos encuentran su origen en "dos lógicas diferentes de activación patrimonial y del presente y pasado étnico, e incluso opuestas y, hasta por momentos, antagónicas" (Crespo 2006: 14). La lógica capitalista de la oferta y la demanda y la búsqueda rápida de ganancias, en la que el patrimonio es un "recurso" destinado a generar ingresos (o rédito político), se contrapone a la consideración de esos bienes como parte del patrimonio de la comunidad, idea en la que prima el interés por su protección dado por el valor científico, estético, histórico que estos bienes tienen para algunos sectores de la sociedad. En los casos en que hemos intervenido, las fronteras entre ambas lógicas son débiles, se atraviesan y diluyen en la práctica, dando un abanico muy amplio de posibilidades en el que, a veces, los sitios con arte rupestre, o bien son ignorados o cumplen un papel de rehén de grupos de poder.

Los arqueólogos somos uno más de los "usuarios" de este patrimonio y priorizamos unos valores por sobre otros. En nuestra práctica, además, encaramos muchas tareas no previstas que demandan buena parte del tiempo y grandes esfuerzos para comprender a los distintos interlocutores y las distintas valoraciones. Esto nos pone en un lugar de reflexión dirigido a cuestionar el monopolio histórico que hemos tenido sobre los bienes patrimoniales y sobre el conocimiento que se genera a partir de ellos. No solamente tenemos que escuchar otras 
voces que interpretan de modos diferentes ese pasado, como se viene reclamando desde amplios sectores, sino, además, compartir con los distintos actores sociales que usan ese patrimonio la responsabilidad de conservar, cuidar y proteger los bienes patrimoniales. Aún cuando los miembros de una comunidad no se identifiquen con él y no lo reconozcan como marcas identitarias porque se ha producido un corte entre este presente y el pasado marcado en las piedras, una vez que lo han hecho propio a partir de considerar sus valores históricos, estéticos, simbólicos, etc., la lógica que prioriza los aspectos económicos deja paso a la conciencia de que se está asumiendo una herencia (Urbano 2000). Ese es el punto de quiebre con la idea instalada en el sentido común de buena parte de los habitantes de la Comarca Andina y valle del río Manso de que esas pinturas en la roca siempre estuvieron ahí, asimiladas al paisaje como una parte más de la naturaleza. Al tomar conciencia de que encarnan procesos que se dieron mucho antes de lo que la historia oficial registra, son reconocidos en sus contenidos históricos y simbólicos (además de los estéticos) y, ahora sí, se los puede poner en valor y abrir al uso público porque al comprenderlos se los valora y se garantiza su conservación.

\section{Notas}

${ }^{1}$ Prats señala las diferencias entre las expresiones "puesta en valor" de un elemento patrimonial y su "activación", entendiendo ésta como el acto de "actuar sobre ellos de alguna forma" (Prats 2005: 19), aunque reconoce que ambas expresiones se utilizan en la actualidad como sinónimos, aclarando que el significado de "poner en valor" es valorar simplemente esos elementos patrimoniales, lo cual constituye una diferencia importante con lo que encierra el concepto de activación. Acá utilizo indistintamente ambos términos para referirme a la valoración de un bien patrimonial y a las acciones que se ejercen sobre él.

${ }^{2}$ En otras oportunidades (Bellelli et al. 2005 y Bellelli 2007) hemos descripto el contexto y las razones de la prohibición de trabajo en el Gran Paredón de Azcona, El Bolsón. Básicamente se debió a la negativa de los propietarios de la chacra para permitirnos realizar los trabajos, después de haber hecho tratativas y tenido amables conversaciones durante varios años en que explicamos el proyecto y sus alcances. Pocos días antes de la campaña programada para el verano de 2004 se produjo la negativa, por lo cual adelantamos las investigaciones en el valle del río Epuyén (Chubut), que estaban planificadas para realizarse después de las de el Gran Paredón de Azcona. Los propietarios del terreno donde se ubica Pataguas tampoco prestaron su colaboración, en cambio sí lo hicieron las dos familias (Azócar y Franzgrotte) que comparten el denominado Risco de Azócar, donde realizamos trabajos durante ese año y el siguiente (Podestá et al. 2007). A ellos y a la Intendencia de El Hoyo (Poder Ejecutivo, Concejo Deliberante y personal administrativo) vaya nuestro agradecimiento.

\section{Bibliografía Citada}

Bellelli, C.

2006 Arqueología y patrimonio. Una historia de usos y abusos en el valle medio del río Chubut (Patagonia argentina). Tramas en la piedra (ed. por D.Fiore y M.M.Podestá), pp. 251-262. INAPL, World Archaeological Congress y Sociedad Argentina de Antropología. Buenos Aires.

2007 Arqueología, patrimonio y turismo. Experiencias de investigación, conservación, manejo y gestión en la Comarca Andina del Paralelo $42^{\circ}$ y valle del Manso inferior. Patrimonio cultural: la gestión, el arte, la arqueología y las ciencias exactas (ed.por C. Vazquez y O. Palacios), pp.8-14. CNEA. Buenos Aires. 
Bellelli, C., V. Scheinsohn, P. Fernández, F. Pereyra, M. Podestá y M. Carballido.

2000 Arqueología de la Comarca Andina del Paralelo $42^{\circ}$. Localidad de Cholila. Primeros resultados. Desde el País de los Gigantes. Perspectivas arqueológicas en Patagonia. Pp.587-602 Universidad Nacional de la Patagonia Austral, Río Gallegos.

Bellelli, C., M. Carballido, P. Fernández y V. Scheinsohn 2003 El pasado entre las hojas. Nueva información arqueológica del noroeste de la provincia de Chubut, Argentina. Revista Werken 4: 25-42.

Bellelli, C., V. Scheinsohn, M. Podestá, M. Carballido, P. Fernández y S. Caracotche 2005 Arqueología, arte rupestre y turismo en la Comarca Andina del Paralelo $42^{\circ}$ (provincias de Río Negro y Chubut). Estudios y Perspectivas enTurismo 14 (1):22-50. Centro de Investigaciones y Estudios Turísticos. Buenos Aires

Bellelli, C., V. Scheinsohn y M. M. Podestá.

2008 Arqueología de pasos cordilleranos: un caso de análisis en la Comarca Andina del Paralelo $42^{\circ}$ y áreas vecinas durante el Holoceno tardío. Boletín del Museo Chileno de Arte Precolombino 13 (2): 37-55. Santiago de Chile.

Bellelli, C. , P. M. Fernández y C. Crespo

2010a Salir del sitio. Una travesía compartida entre arqueólogos y antropólogos. Relaciones: 279-287. Sociedad Argentina de Antropología. Buenos Aires.

Bellelli, C., M. Podestá, N. Carrasco, B. San Martín, V. Rogante, R. Font y S. Caracotche 2010b El patrimonio en nuestras manos. Relevancia de la Comisión de Sitio local en la gestión de un sitio arqueológico con arte rupestre. Bienes culturales, turismo y desarrollo sostenible (Experiencias de España y Argentina), (ed. por J.Marcos Arévalo y R.E.Ledesma), pp. 213-235. Signatura Ediciones. Sevilla, España.

Caracotche, M.S., L.Margutti y S.Cabrera

2010 Memorias para las historias del Manso. Administración de Parques Nacionales Delegación Regional Patagonia, Parque Nacional Nahuel Huapi. Bariloche.

Crespo, C.

2006. Entre el 'deber`y el 'derecho': patrimonio arqueológico y obligaciones mutuas en Patagonia Argentina. Intersecciones en Antropología 7: 63-76.

Fernández, P.M., M. Carballido Calatayud, C. Bellelli, M. Podestá y V. Scheinsohn. 2011 Marcas en la piedra, huellas en la tierra. El poblamiento del bosque del suroeste de Río Negro- noroeste de Chubut. Procesos históricos, transformaciones sociales y construcciones de fronteras. Aproximaciones a las relaciones interétnicas. Estudios sobre Norpatagonia, Argentina y Labrador, Canadá, (ed. por S. Valverde, G. Maragliano, M. Impemba y F. Trentini), pp. 195221. Editorial de la Facultad de Filosofía y Letras Universidad de Buenos Aires

Gándara, M.

2009 El estudio del pasado: explicación, interpretación y divulgación del patrimonio. Cuadernos de Antropología 5: 97-123. Programa de Arqueología Histórica y Estudios Pluridisciplinarios. Universidad Nacional de Luján. 
Masotta, C.

2001. Marcas del tiempo en Cholila. Gente y relatos de la Patagonia. Video (55’). Biblioteca y videoteca del INAPL y cmasott@hotmail.com.

2004. El Paisaje Encantado. Turismo y arqueología en el valle del río Manso. Video (`30). Biblioteca y videoteca del INAPL y cmasott@hotmail.com.

2010. El fantasma del cacique Foyel. Video (30’). Biblioteca y videoteca del INAPL y cmasott@ hotmail.com.

Moscovici Vernieri, G.

2011 Viaje al otro lado del puente. Novedades del Instituto Nacional de Antropología y Pensamiento Latinoamericano 69: 14-17. Buenos Aires.

Ondelj, M.

2004. Memoria Social en la Patagonia Argentina. El Pasado en el Presente de Cholila. Tesis de Licenciatura en Ciencias Antropológicas, Facultad de Filosofía y Letras, Universidad de Buenos Aires. Ms. Biblioteca Central de la Facultad de Filosofía y Letras, UBA.

2005. ¿Qué ves cuando me ves? El problema de la comunicación de sentidos en relación al patrimonio cultural. Turismo Cultural. Pp.159-170. Comisión para la Preservación del Patrimonio Histórico Cultural de la Ciudad de Buenos Aires.

Podestá, M.; Bellelli, C.; Fernández, P.; Scheinsohn, V.; Carballido Calatayud, M.; Forlano, A.; Marchione, P.; Tropea, E.; Vasini, A.; Alberti, J.; Gallo, M. y Moscovici Vernieri, G. 2007. Arqueología del valle del río Epuyén (El Hoyo, Chubut, Patagonia argentina). Arqueología de Fuego-Patagonia. Levantando piedras, desenterrando huesos... y develando arcanos. (ed. por Morello,F. M. Martinic, A, Prieto y C.Bahamonde), pp. 427-442. Ediciones CEQUA. Centro de Estudios del Hombre Austral, Instituto de la Patagonia-Universidad de Magallanes, Punta Arenas, Chile.

2009 Podestá, M. M., C. Bellelli y M. S. Caracotche

El sitio con arte rupestre Cerro Pintado. Hacia la construcción de un espacio de gestión entre lo público y lo privado. Crónicas sobre la piedra. Arte rupestre de Las Américas (ed. por M. Sepulveda, L. Briones y J. Chacama), pp.73-88. Ediciones Universidad de Tarapacá, Chile.

2005 Prats, Ll.

Concepto y gestión del patrimonio local. Cuadernos de Antropología Social 21:17-35.

Urbano, $\mathrm{H}$.

2000 Patrimonio y modernidad. Turismo y patrimonio 1:13-25.

Xicarts,D.

2005. El patrimonio arqueológico como recurso turístico. El caso del Valle del Río Manso inferior - Argentina. Estudios y perspectivas en turismo 14(1): 51-71. Centro de Investigaciones y Estudios Turísticos. 